\title{
Sciendo
}

Administration, vol. 68, no. 4 (2020), pp. 55-72

doi: 10.2478/admin-2020-0024

\section{Leading public service reform: Some reflections}

\author{
Robert Watt \& Michael Perkins* \\ Department of Public Expenditure and Reform, Ireland
}

\begin{abstract}
The past decade has been a period of intense reform, bookended by two crises of seismic proportions - the troika bailout of Ireland in 2010 and the Covid-19 pandemic in 2020. This paper details the reforms which have been led by the Department of Public Expenditure and Reform over the past decade. Also, drawing on Robert Watt's reflections of leading public service reform, it sets out lessons learned and factors which we regard as necessary to ensuring successful reform. Finally, a range of priority areas for the future are identified.
\end{abstract}

Keywords: Reform, leadership, renewal

\section{Introduction}

In March 2011 the newly elected Fine Gael/Labour Government announced the establishment of the new Department of Public Expenditure and Reform (DPER), into which were transferred the public expenditure management functions ('vote sections') and the Pay and Industrial Relations Divisions of the Department of Finance. These divisions were reinforced by the transfer of the Reform Division in the Department of the Taoiseach, with further divisions added as the department became established.

* We would like to thank our many colleagues in DPER and other departments for their reform efforts over the last decade. In particular, we would like to acknowledge the contribution of the current Head of Reform, Dr Lucy Fallon-Byrne. 
Reform ${ }^{1}$ had been a central, albeit ill-defined, theme of the recently held general election. The election campaign was dominated by the economic and banking collapse, which was marked by the Bank Guarantee in September 2008 and Ireland's eventual participation in the IMF troika funding programme in November 2010. A number of policy failures had characterised the period preceding the crash, most notably the failures of the Financial Regulator and the Central Bank of Ireland to safeguard financial stability. The Department of Finance was also heavily criticised at the time for inadequately warning against inappropriate fiscal policies and for allowing macroeconomic imbalances to emerge.

In this atmosphere, where much criticism was directed at the public sector, ${ }^{2}$ economic, financial, banking and fiscal frameworks had to be redesigned to avoid such mistakes reoccurring in the future. There was also a specific agenda to increase accountability and improve the overall quality of decision-making and transparency in public administration. The newly appointed Minister for Public Expenditure and Reform, Brendan Howlin, TD, was the inspiration behind much of this agenda and whilst in office he led this extensive programme of legislative change, which included:

- the extension of the Ombudsman's jurisdiction and powers;

- provision of a detailed legislative framework for parliamentary inquiries;

- the regulation of lobbying;

- an extensive reform and extension of the Freedom of Information Act;

- comprehensive employment protection to whistle-blowers in all sectors of the economy, including members of An Garda Síochána and the Defence Forces;

- an overhaul of the system for appointments to state boards.

At the same time, discussion on broader civil service and public service reform was mixed: apart from broad commitments to fewer management layers and more freedom for managers to manage staff

\footnotetext{
1 There is much confusion about the meaning of reform. Reform of economic, banking and social policies, inter alia, are not the focus of this discussion. Our focus is on reform of structures, practices and systems of civil and public service bodies to improve their performance in terms of overall efficiency and effectiveness.

${ }^{2}$ Much of the most divisive coverage was led by newspapers who had been enthusiastic cheerleaders for the easy credit and loose fiscal policies that led to the collapse.
} 
and budgets, an agenda for reform to guide a revitalised civil service was largely absent during the election campaign. The party manifestos had some references to reforms to organisational structures and culture: Fine Gael, for example, highlighted the need to 'cull' the number of public sector quangos, the Top Level Appointments Committee was to be revamped, legislation was to make ministers and senior civil servants legally accountable for their decisions and management of their departments, and the boards of certain state agencies were to be abolished, with managers made accountable directly to ministers. Ultimately, much of the debate and discourse on reform amounted to no more than point scoring; 3 there was relatively little by the way of concrete ideas, or even less of a coherent framework within which to consider Ireland's civil service, its evolution, failings, achievements and future role.

This was the backdrop to the new department's creation. Its main function, working with the now significantly changed Department of Finance, was to reduce public expenditure, close the fiscal deficit and meet the terms of the troika programme. Combined with the downsizing and restructuring of the banking system (and wider structural reforms), these measures focused on economic recovery and exit from the programme. Reform was essentially a secondary objective. Some reforms, as shall be discussed later, enabled and complemented the necessary fiscal consolidation - others were unrelated and part of the wider legislative reform programme ${ }^{4}$ or part of non-budgetary related reforms.

\section{New departmental structures}

Ireland's patchy record of delivery of previous civil-service-wide reforms suggested that for such programmes to be effective, they needed to have clear structures, reporting mechanisms and organisational coherence. DPER had the critical functions needed for this task. Reform elements heretofore in the Department of the Taoiseach were now aligned with the department's spending-control divisions - this avoided potential disputes over resources as the reform measures had to be consistent with, and supportive of, the fiscal

\footnotetext{
${ }^{3}$ For some this simply meant cutting public sector salaries and making it easier to fire public servants.

${ }^{4}$ William Beausang, an assistant secretary in the department, led a small and very dedicated team who delivered on this complex and wide-ranging agenda.
} 
consolidation agenda. The objectives of reform and industrial relations policy became similarly aligned. During the period of social partnership it had been felt by many that necessary reform to structures was stifled by the need to achieve 'consensus' before steps were taken. In many instances, this amounted to a veto exercised on behalf of the trade unions. With these elements now located within one government department, a consistent approach could be achieved between reforms, expenditure decisions, pay and industrial relations.

Programme change requires a dedicated structure to drive and lead across many sectors, departments and offices, so a Reform and Delivery Office $(\mathrm{RDO})^{5}$ was established to provide this. The RDO drafted the first public sector reform programme, which set the highlevel priorities, a detailed set of actions, milestones and responsible owners. This amounted to a detailed plan with a standard traffic-light system to be reviewed regularly by managers in the department, with reports submitted quarterly to a cabinet committee, chaired by the Taoiseach, to review progress on the implementation and address strategic issues arising. The cabinet committee was supported by an Advisory Group of Secretaries General and a Reform Delivery Board that included the assistant secretaries leading on reform in all departments and major offices. Project boards were established for the major projects under the reform plan, which ensured clear administrative accountability as well as political ownership.

Experience suggested that programme change in resistant organisations with powerful trade unions, and variable management capability, was a challenge. Structures are important - but another essential ingredient is committed leadership. The new department had strong political support but internal reform (other than in pay matters) was not high on the political agenda, especially in the midst of the wider challenges the system faced during this period. There was support also amongst many - but not all - of the secretaries general. This is a challenge in our devolved system: we needed a consistent approach to horizontal reform but individual leaders are independent accounting officers. The legislative structures for accountability mean that cooperation across the civil service needs a driver - it is not spontaneous, and senior colleagues could not be compelled to follow. This is always a challenge in a centrally driven reform process requiring effective cross-government governance arrangements for oversight and compliance.

\footnotetext{
${ }^{5}$ Paul Reid, the current head of the Health Service Executive, was the first leader of the office and played a critical role in leading many of the reform elements.
} 
The department was established, therefore, with the clear responsibility to programme manage reform from 'the centre', creating a common reform platform for other government departments and agencies and leading the negotiation of the overarching programme with unions, particularly on pay and productivity matters.

\section{Reform priorities}

These were the structures created to deliver a reform agenda - but what about the content of the plan?

As we mentioned above, the political system provided significant impetus on many aspects of reform. Measures in relation to changes to the freedom of information legislation, new lobbying legislation, ethics reforms and changes to the board appointment process were driven by a clear political agenda. Reducing the number of public bodies also featured strongly.

Initial measures to reduce expenditure and improve efficiency and effectiveness of delivery were essential, but the impetus for many of the subsequent reforms had to be developed. Minister Brendan Howlin set the values, goals and direction of a more effective system and officials were mandated with providing him with a credible plan. The economic crisis created a 'burning platform' from which to drive efficiency and to modernise public service delivery: we had the burning platform but needed more in terms of scaffolding.

The first public service reform plan (encompassing, at that point, all the major sectors, including the civil service) was based on a modernising agenda drafted by the team in the RDO (subsequently joined by the programme director, Paul Reid) with inputs from many colleagues across the civil service. ${ }^{6}$ The vision was to implement a series of reforms and measures in order to modernise the public service. Paul Reid had a strong operational background and a clear view on changes to work practices, digital investments, shared services, procurement and much more. Robert Watt brought his own perspectives based on his experiences working in the Department of Finance and having spent eight years working as a consultant, which gave him the opportunity to see the workings of many public and private bodies, both in Ireland and internationally.

${ }^{6}$ Philip Kelly, the assistant secretary in the Department of the Taoiseach, had developed a comprehensive programme of reform. Many of these were subsequently adopted and included in the first reform plan. 
His return to the Department of Finance in 2008 gave him a sense of the systems' strengths and weaknesses. We had hugely talented staff but too many generalists and not enough specialists. There had been a time where he felt the Department of Finance, in particular, had a very strong intellectual culture: he found that this had been eroded. The decline in basic economic skills in the department and across the civil service was notable. This led to a policy formation culture that was less than optimal. Policy development requires core skills and competences, which were increasingly being outsourced without sufficient in-house ability to challenge or scrutinise. The policy formation process needed to be shaken up. On becoming Secretary General of the new department, he was determined that a more genuine spirit of openness and inquiry would be encouraged and a new cadre of officials would be developed. Policy could be improved through better use of data, more joined-up data, greater expertise, and more outside scrutiny and engagement. The establishment of the Irish Government Economic Evaluation Service (IGEES) emerged from this process.

Other areas also needed radical change. Recruitment to the civil service was mostly closed, apart from entry grades and roles at assistant secretary level. There was no senior people service, and not too much focus on succession planning, learning and development, and leadership skills development. Skills such as IT, HR, finance and economics were not sufficiently developed. The underdeveloped IT systems across much of the civil service and the narrow focus taken to ICT and digital opportunities were striking: there was no Irish Government Chief Information Office in 2011 - an omission that we addressed. Moreover, there were no formal heads of economics, procurement or shared services. ${ }^{7}$

In broad terms, Robert Watt had some basic reform ideas about digital, data, professionalisation, policy formation, recruitment practices, innovation and HR. Paul Reid shared many of these concerns and augmented the list with perspectives on matters outside of Robert Watt's area of expertise such as HR, work practices, organisational structures, shared services, procurement and much more. They also sought to build on the many initiatives started by Philip Kelly in the Department of the Taoiseach.

In summary, the new department was established with a responsibility to programme manage reform from 'the centre', creating the

${ }^{7}$ Plans for a common HR transactional services platform were developed but not yet implemented. 
common reform platform for departments and agencies, and leading the negotiation of the overarching programme with unions, particularly on pay and productivity matters. Shared-service delivery offered a model proven worldwide for enabling efficiency and consistency, leveraging common ICT platforms and allowing government bodies to focus on their core responsibilities: its adoption needed to be accelerated.

At the core was a fundamental view that process improvement, better governance, modern IT systems/work practices, and professional recruitment/HR and systems were key to improving performance. Finally, policymaking needed to be grounded in better evidence-based analysis.

\section{Key elements of the 2011 public service reform plan}

As we have described already, the department's RDO was established to oversee implementation of reform across the system, led by a programme director with experience of delivering major transformational change. Within this overarching framework, departments, offices and bodies established their own change delivery teams to manage and drive the reform process in their organisations and sectors.

Key priorities of the plan included, for example, more digital delivery of services, improved engagement with customers, the use of alternative models of service delivery, implementation of shared services, more efficient and effective public procurement and property management, and increased openness, transparency and accountability. The RDO coordinated and monitored the implementation of more than 230 actions, compiling reports on progress on a quarterly basis.

Significant cost reductions and productivity increases (e.g. additional working hours) were made possible by the Croke Park and Haddington Road Agreements reached with public service trade unions. Greater workforce flexibility and new working arrangements were introduced as well as strengthening senior management and leadership capacity. By the end of 2014, public service staff numbers had been reduced by approximately 10 per cent since 2008 and the public service pay bill had reduced by over 20 per cent since 2009, all at a time of increased demand for public services arising from demographic changes, as well as from the financial crisis. The reduction in staff numbers was a key factor in reducing the cost to the 
Exchequer of the pay of public servants from $€ 17.5$ billion in 2009 to $€ 14.1$ billion in 2013.

Shared services were introduced in the civil service and in sections of the wider public service: PeoplePoint, the civil and public service $\mathrm{HR}$ and pensions administration shared service centre, went live in early 2013. Actions were taken to make access to public services easier and more streamlined, such as the Public Services Card and the increased availability of information and online services.

The Office of Government Procurement, headed by a new chief procurement officer, was created to lead a major efficiency drive in public procurement across the public service and achieve maximum value for money. As mentioned, IGEES was set up as an integrated cross-government service, to enhance the role of economics and valuefor-money analysis in public policymaking.

A series of reforms brought greater structure, scrutiny and openness to the government's annual budget. Adoption of a 'whole of year' approach gave the Oireachtas the opportunity to debate the allocation of resources for the current year and engage in constructive dialogue with ministers and their departments on spending plans for the following year and the prioritisation of spending areas.

Building on progress made under the 2011 reform plan, the second public service reform plan (2014-16) placed greater emphasis on improving service delivery, while still maintaining the necessary focus on ensuring efficiency and value for money. The priorities were service users; efficiency; openness, transparency and accountability; as well as leadership, renewal and organisational reform.

A new chief information officer was appointed to provide guidance and leadership at the executive level across the entire IT spectrum, and take responsibility for developing a new Public Service ICT Strategy, published in January 2015, in order to create a new model for ICT delivery across the public service. Major alternative servicedelivery initiatives were implemented, such as JobPath and the call centre for the Local Property Tax, as well as the radical reorganisation of some key cross-cutting functions and the evaluation of new business models for the delivery of certain activities such as debt management.

Our Public Service 2020 (OPS2020) - the third phase of public service reform, published in late 2017 - sought to build further on these reforms while expanding their scope to focus more on collaboration, innovation and evaluation. While OPS2020 reemphasises the importance of digital delivery and using data to achieve greater efficiency, it also has a strong focus on organisations 
and people, with actions in areas such as strategic HR, employee engagement, performance management, and culture and values:

- driving digital delivery of services, including, for example, An Garda Síochána's Active Mobility Service; Passport Online; Library Service's My Open Library initiative; Revenue Commissioners PAYE Modernisation programme;

- driving the take-up of robotic process automation (RPA), including the establishment of procurement frameworks to enable drawdown of support and expertise;

- an Innovation Fund to support public service innovation and the establishment of a central Innovation Support Team;

- a significant strategic workforce planning initiative in selected public service organisations and an initiative to support greater diversity and inclusion in the public service.

Implementation of this plan was underpinned by new sharedownership structures across the public service and a strong emphasis on evaluation of reforms. A Public Service Leadership Board was established to bring together participants at secretary general and CEO level from across the civil and public services to drive the reform agenda and lead on its implementation.

\section{Renewal of the civil service}

While civil service elements were an integral part of this wider public service reform plan, a specific agenda was subsequently worked up for a renewal of the civil service. The outcome was the Civil Service Renewal Plan, a single coherent programme of change aimed at strengthening capacity, capability, accountability and leadership throughout the civil service, which was published in late 2014. The significant progress made in bringing about these changes has been documented in a number of progress reports since. Particularly important from our point of view was the emphasis put on strategic HR management and employee engagement - two areas that had not featured prominently in other reform initiatives.

The renewal plan notably provided for the establishment of a Civil Service Management Board (CSMB) to collectively oversee renewal actions and provide a forum for discussing strategic and systems-level issues facing the civil service. Secretaries general and heads of major 
offices now provided visible leadership on these issues within the CSMB, where perhaps in the past this would have been seen more as a central function. The CSMB has served to bring a whole-ofgovernment perspective to the civil service renewal agenda and its structure has helped to maintain momentum and drive and to embed reform in key areas.

\section{Impacts - What succeeded and where further efforts are required}

Looking back now over what has turned out to be a period of rapid change, bookended by crises of very different origins, both of which posed unprecedented challenges for the state, it is possible to assess the changes to the civil service that were delivered.

With the onset of the crisis from 2008 and a collapse in tax revenue, it soon became clear that the public service pay and pensions bill had to be reduced. Measures were necessary to reduce public service numbers and rates of remuneration. The Exchequer pay bill was cut by $€ 3.7$ billion during the crisis period through a moratorium on recruitment (which reduced public service numbers by 32,000) and the extraordinary emergency pay legislation (FEMPI), which generated $€ 2.1$ billion in pay savings with additional savings on pensions in payment. The Single Pension Scheme introduced in 2013 represented a significant reform of public service pensions. Applying to all new entrants from 1 January that year (as well as previous public servants with a break in service of more than twenty-six weeks), the scheme is projected to reduce expenditure on public service pensions by 35 per cent, mainly through three reform measures - later normal retirement ages, a career-averaging method of calculating benefits and the application of CPI indexation.

The new Public Service Sick Leave Scheme, commenced at the end of March 2014 (1 September 2014 for the education sector), reduced the cost and incidence of sick leave by effectively halving the period of time for which paid sick leave is available. Prior to these reforms, the cost of sick leave for the public service had been valued at $€ 500$ million. Cumulative savings from 2013 to 2018 have been estimated at $€ 156$ million.

Hence, measures to reduce pay and related costs and to increase hours had a clear impact. These measures, in as much as they were associated with the same level or higher output, increased efficiency. 
Of course, policy measures led to a subsequent increase in wage costs and diluted some of the impact of these reforms.

Wider HR and recruitment also had an impact, and with potentially longer-lasting consequences. Recruitment and promotion processes were overhauled to better meet a number of important objectives, including aligning recruitment and selection with business needs; ensuring skilled candidates have access to the breadth of opportunities; and ensuring managers can draw on the widest possible pool of available talent, including external candidates. Open recruitment has enabled the civil service to compete with other major employers for professional and technical staff, and has broadened our talent pool. We are now a far more diverse organisation in terms of experience and particular skill sets.

Since its establishment in 2012, IGEES has grown substantially from around 30 staff to 200 in 2019 - with network members placed across all government departments. IGEES has helped to deliver more than 200 analytical papers in a variety of policy areas, including spending reviews - with about 80 published. A 2019 OECD study on the extent to which IGEES has contributed to putting evidenceinformed policymaking into action found that it has had a significant impact overall in strengthening the analytical capacity of the civil service and building a robust evidence base for better policy- and decision-making in a context where human resources are relatively constrained.

More broadly, the reforms undertaken for appointments to state boards, notably the guidelines published by the department in 2014, greatly enhanced the process, and a dedicated website was created to meet the government request for increased transparency. In spite of some concerns in the early stages that the new process would not attract appropriately qualified applicants, the experience to date is that the process has worked well. There has been a steady flow of competent and appropriately qualified candidates with different expert perspectives, brought through an open and transparent process for consideration and eventual appointment by ministers to state boards.

Investment in training and development has been overhauled. Following a period of retrenchment, the 2014 Civil Service Renewal Plan set out a new approach for a shared learning and development service. OneLearning was established in 2017 to centrally operate and maintain a new L\&D model for the civil service and to manage the delivery of the new common suite of programmes. Uptake has been 
encouraging - since September 2017, when OneLearning's operations commenced, training has been delivered to over 27,500 attendees in 44 civil service bodies in 25 counties (up to the end of 2019).

The introduction in 2015-16 of performance review processes for secretaries general and posts at assistant secretary level (a key priority of the Civil Service Renewal Plan) means that there are now formal performance review processes at all levels of the civil service. At secretary general level the process is overseen by a Performance Review Group, which comprises the Secretary General to the Government, the Secretary General of DPER and an external member, which brings additional rigour and consistency. The emphasis is on effective feedback about what is done, how it is done and, importantly, how things may be done better through supports and personal and professional development.

'Build to Share' - a central pillar of the Public Service ICT Strategy adopted in 2015 - provides a shared model for ICT service delivery that supports integration and sharing of resources across the wider public service while driving efficiency and controlling costs. The Build to Share suite now includes a range of government networks, applications, managed ICT services, government cloud infrastructure and a government data centre - currently used by a very broad base of public service clients, in contrast to the sometimes uneven and disjointed approach to development of ICT capacity in the past.

The Financial Management Shared Service project, a service-wide IT upgrade and standardisation project led by the National Shared Service Office (NSSO), promises many benefits, creating a platform that can meet the needs of government departments and eliminating the need for many separate upgrades. Unfortunately, the project has been affected by delays, technical problems and financial overruns over recent years. Generally, implementation of common ICT platforms, in areas such as HR and finance, has proved very challenging, particularly given the earlier inconsistent, fragmented approach. While the original conception has not met its planned timelines, the NSSO has recently completed a redesign of the project and is expected to put in place a revised timeline for rollout shortly.

We have become increasingly aware of the value of data as a strategic asset for the public service, and that our approach to its collection, management and sharing needs to improve. The National Data Infrastructure was developed to ensure the collection and storage of three key identifiers on all public sector data holdings, when 
they relate to relevant transactions with customers: the PPSN for interactions between the individual and the public sector; the Eircode for location of individuals/businesses; and a unique business identifier, to allow improvements in service delivery, and policy formulation and analysis for businesses interacting with the public sector. The Data Sharing and Governance Act passed in 2019 laid down a general legal basis for public bodies to share data for specified purposes in a manner compliant with GDPR, thereby reducing administrative burden and simplifying the provision of services.

It is clear that digital services and e-government are key to improving service delivery, by making services more accessible, further engaging the public, and driving efficiency and effectiveness. However, while we have made significant investments in enabling technologies and infrastructures to accommodate this, the slow pace of digital transformation across the civil and public service when benchmarked against our peers gives cause for concern. ${ }^{8}$ The creation of the Digital Leaders Group and the decision to set a target of 90 per cent of government services delivered digitally may help to address this, but continued leadership at the most senior levels will be required to embed the digital transformation.

As the state spends approximately $€ 15$ billion per annum on goods, services and works, a strategic and coordinated approach to public procurement is also vital. The Office of Government Procurement's establishment in 2013, with responsibility for the overarching policy framework, combined with a shift to a more centralised model of procurement for significant categories of goods and services, allowed us to better leverage the state's purchasing power and speak with one voice to the market. While considerable progress has been made, many further opportunities and challenges fall to be addressed in the next phase of the procurement reform programme. Improvements in governance, engagement, programme management, professionalisation, digital transformation and construction procurement reform are some of the key focus areas.

${ }^{8}$ The Digital Economy and Society Index, compiled annually by the European Commission, tracks member state progress in 'digital public services'. While Ireland rated well overall in the recently published 2020 review, it ranked ninth in digital public services, dropping one place since 2019. Furthermore, the International Civil Service Effectiveness Index, which assesses the performance of central civil services around the world, placed Ireland twenty-sixth out of thirty-eight countries in the area of digital services. 
Accountability has, quite rightly, featured strongly in our political discourse and been the subject of much academic and media comment, as well as public discussion, since 2008 - we have already set out the reforms driven by Minister Brendan Howlin and the department that impact accountability in its various aspects. Regrettably, the Accountability Board established for the civil service under the auspices of the Independent Panel chaired by Professor Kevin Rafter (and following extensive public consultation) has had, in practice, limited reach. If such a structure is to play a role in accountability at an overall systems level, further reflection is required along with understanding of how it will work to enhance existing accountability arrangements.

\section{Next steps}

Many of the developments that we have touched on here have had a positive and beneficial impact. These include:

- the build-to-share ICT infrastructure and increasingly common practices across the civil service;

- progressive digitalisation of services;

- a streamlined and centralised government procurement system;

- shared services;

- more specialist recruitment, including IGEES;

- more investment in leadership, succession planning, and learning and development;

- centralised strategic HR capability.

Many of these developments must be augmented and will become even more relevant as we seek to navigate future challenges.

With digital and mobile devices becoming ubiquitous, individuals and businesses expect to have seamless digital interactions with government services. The benefits are well established - efficiency, transparency, trust and accessibility, as well as resources that can be released for improving existing and future services. In particular, this also presents the public service with a fresh and exciting opportunity to embed a 'citizen-focused' approach to service delivery in a comprehensive and systematic way.

While the systems that we operate have undergone major reform, the environment is changing even faster and public service bodies have not always embraced the changes as quickly and fully as they might 
have done. The civil service needs to be more agile in terms of digital technology and deliver more citizen-centric innovative services in order to keep pace with the public's ever-increasing expectations. Substantial opportunities also present themselves in the areas of:

- roll-out of RPA to replace slow, time-consuming manual processes;

- increased use of data, open data and modelling to provide evidence and insight for policy and decision-makers;

- fully developing the National Data Infrastructure and resolving the policy issues that can inhibit achievement of best policy outcomes and exploiting data as an enabler.

An increasing reliance on data, underpinned by improved data quality and more and better reuse of data, will require us to put the right to privacy and data protection at the heart of our approach, so that the personal data that we collect is always stored, processed and shared appropriately.

Flexible working and new work practices, notably a major increase in remote working and mobility, have played a central role in our adaption to the circumstances of the Covid-19 pandemic, underlining the strategic importance of the HR management function and common technology infrastructure. A flexible approach will continue to be required to ensure value for money and maximise talent and performance of the workforce.

A reconfiguration and integration of traditional services to provide one-stop-shop facilities in local and regional centres will allow the public to access all government services in one location and assistance where necessary in accessing digital services. This can also allow civil and public service staff to work locally, avoiding long commutes and rebalancing staff in the regions and away from the cities.

We must also focus on developing high-performing leaders leaders who are visible and effective in their capacity to manage and develop their organisations and staff, can communicate strategic priorities and vision to their teams, and can work collaboratively and innovatively on whole-of-government projects. In particular, they should encourage their staff to take on manageable levels of risk and, when inevitable setbacks occur, move forward quickly while harvesting the valuable learning opportunities that can ultimately lead to successful and sustainable innovations. We should target a culture of innovation that supports the exploration and adoption of new approaches to policy and service delivery challenges whilst also managing risk. 
To absorb the impact of our ageing staff population and the competitive labour market, the civil service needs to consolidate its position as an employer of choice and ensure that our end-to-end recruitment and selection processes are fit for purpose and can continue to compare favourably with other leading private and public sector employers.

The majority of the work of the civil service remains in policy formulation and administration, and so we rely on a cadre of professional public administrators often referred to as generalists to undertake this. However, the changing business environment that we describe increasingly calls for their expertise to be augmented by qualified specialists in areas such as finance, ICT, HR, procurement and communications. We are addressing this challenge but need to do more by both growing our own staff through in-house professional development and direct recruitment into, and development within, professional work streams. As we have already indicated, a greater role for such professionalisation can be envisaged as we adapt ourselves to meet the future (it is also important to note that, outside corporate functions, we have always had many defined professional/ technical roles, and such pathways currently make up approximately 20 per cent of the civil service's staff).

\section{Leading reform - Lessons and conclusion}

With substantial elements of the agenda launched in 2011 now bedded down, it is possible to identify the presence of some of the key ingredients required to deliver an extensive reform programme. These include:

- a clear and widely accepted rationale for change (why it is required and the goals that are targeted);

- an ambitious but realistic agenda;

- engaged leadership and direction;

- high-level, cross-cutting leadership structures for oversight and compliance;

- a willingness to allocate the resourcing and investment to enable delivery.

It is also a good point to try to judge exactly how successful this cycle of reforms has been - which in turn raises another fundamental question: how do we measure success in the public sector context? 
A hallmark of our current approach is seeking to move the focus of reform to better target outcomes. This aligns, inter alia, with the OECD's recommendations in its assessment of the Public Service Reform Plan 2014-2016. As the OECD assessment points out, emphasising outcomes requires us to 'ensure the necessary data and indicators to measure progress towards achieving those outcomes'. Throughout his research career, Richard Boyle in particular has been at the forefront on this issue, identifying appropriate indicators for an Irish public sector context that can serve to:

- support enhanced service delivery and value for money;

- inform evidence-based policymaking (and consequent greater accountability to the public);

- embed evaluation culture across the civil and public service with a performance-outcome focus.

In particular, timely evaluation now by public service organisations of their responses to the Covid-19 pandemic, based on appropriate indicators, will also be invaluable in navigating the post-crisis environment, and in informing the potential for new delivery systems for public services and the implications for the future of our work in changed circumstances.

The truism that 'culture eats strategy for breakfast' applies as much in the civil service as in any other organisation. With this in mind, it is opportune for us to undertake some deep reflection on the right ingredients for a culture that will enable the civil service of the future to continue to deliver. We have already mentioned the importance of leadership - empowerment is another key ingredient, as are commitment by all staff to high standards and an ethos of public service. Scrutinising our performance, celebrating and recognising our success while acknowledging our failings and learning from them are also essential. Understanding the needs of customers and stakeholders and remaining open to new ideas on how to improve what we do should also feature prominently.

To ensure that we continue to meet the needs of government and the public, we have to be open to change in the ways we work and deliver public services - as we have just demonstrated in our response to the Covid-19 pandemic, we are capable of doing so. As we write, an ambitious ten-year strategy and vision for the civil service is in preparation to enable such transformation to occur over the next decade. An analogous exercise is underway for the public service. 
Achieving the right culture that can empower our people to innovate, while being rooted in a common purpose and values, will be key to securing that transformation.

As to the future of DPER itself - and its relationship with the Department of Finance - the recently formed government has made a clear decision to maintain the status quo, so we can assume that the overall administrative approach we set out above will continue in the medium term. The distribution of policy portfolios among ministers is a government matter but, in our experience, the current structure works well and enables both organisations to deliver on their respective mandates. 